\title{
Co-Pyrolysis of Low-Density Polyethylene and Motor Oil-Investigation of the Chemical Interactions between the Components
}

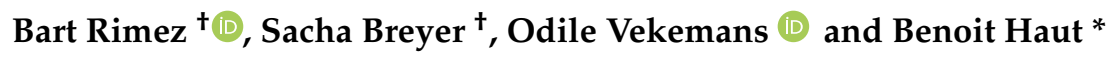 \\ Transfers, Interfaces and Processes (TIPs), Chemical Engineering Unit, Free University of Brussels, \\ Av. F.D. Roosevelt 50, 1050 Brussels, Belgium; bart.rimez@ulb.ac.be (B.R.); sachabreyer@hotmail.com (S.B.); \\ ovekemans@innoviris.brussels (O.V.) \\ * Correspondence: bhaut@ulb.ac.be \\ $\dagger$ These authors contributed equally to this work.
}

Received: 11 September 2020; Accepted: 9 December 2020; Published: 14 December 2020

\begin{abstract}
In this work, different thermal analysis methods have been used to study the co-pyrolysis of low-density polyethylene (LDPE) and motor oil. Two kinds of motor oil were considered, a fresh one and a used one. Through the comparison of experimental curves and so-called "theoretical curves", high-resolution thermogravimetry experiments allowed highlighting interactions between the LDPE and each of the two oils, when they are co-pyrolyzed. While thermogravimetry coupled with mass spectrometry did not give any insights into these interactions, pyrolysis coupled to gaseous chromatograph and mass spectrometry allowed identifying aldehydes in the products of the co-pyrolysis of LDPE and each of the two oils. These aldehydes were not observed during the pyrolysis of the LDPE or the oils alone. On the basis of these results, various explanations for the formation of these aldehydes are proposed.
\end{abstract}

Keywords: co-pyrolysis; plastics; oils; decomposition; mechanism

\section{Introduction}

Over the past few years, chemical recycling of waste plastics received a great deal of attention as it offers an interesting valorization alternative for plastics unfit for mechanical recycling. Among the available processes, pyrolysis and co-pyrolysis have been technologies of choice because of their ability to produce a liquid fraction similar to commercial gasoline [1]. In order to alleviate technical limitations related to plastic behavior at high temperature, co-pyrolysis of waste plastics and other materials has been widely considered. Beneficial synergistic effects (increasing gas and liquid yields, decreasing tar and char yields, improvement and stabilization of the pyrolysis products) have been reported for the co-pyrolysis of plastic and biomass [2-5], plastic and oil shale [6], plastic and cellulose [7], polyethylene and waste newspaper [8], as well as waste polyolefins and waste motor oil [9]. Kim et al. [10], in line with one of our previous works [11], show a thermal stabilization effect during the co-pyrolysis of waste automobile lubricating oil and polystyrene (i.e., degradation temperatures of the mixture shifted towards higher values, when compared to the pyrolysis of the pure compounds). A thermal stabilization effect of inorganic materials on the lignocellulose fraction in construction and demolition waste was also mentioned by Castaldo et al. [12], and Avella et al. [13] highlighted that compatibilizing agents induce a thermal stabilization of plastic and cellulose in composite material.

Generally, in all these studies, no clear pathway is proposed to explain the reported interactions between the components. Consequently, the objective of this work is to give more insights into the interactions between plastics and oil during their co-pyrolysis. As low-density polyethylene (LDPE) is 
the most common plastic packaging material, it has been selected for this work. Two kinds of motor oils were considered: an unused motor oil and a recycled one. Two analytical techniques, classically used to characterize the thermal decomposition of polymers [14,15], were applied on the mixtures and on the plastic/oils alone: Thermogravimetry coupled with Mass Spectrometry (TGA-MS) and Pyrolysis coupled to gaseous chromatograph and mass spectrometry (Py-GC/MS). The results obtained with these techniques are compared in this paper in order to characterize the interactions between the LDPE and the oil during their pyrolysis and to propose underlying mechanisms.

\section{Materials and Methods}

\subsection{Materials}

The polymer used was LDPE, provided by TOTAL FELUY SA (Belgium). Two types of oils were used: a fresh, unused motor oil commercialized by TOTAL (Classic 10W40) and provided by TOTAL FELUY SA (Belgium), referred to as the "motor oil", and a mixture of used motor oils, collected by GEOCYCLE, a subsidiary of the HOLCIM group, referred to as the "used oil". Used oil is a mixture of oils with a large variety of lifetime in different motor blocks. It has therefore undergone stress, friction, and exposition to high temperatures of unknown nature. Most probably, it is composed of partially degraded oligomeric chains.

\subsection{Composition of the Oils}

The used oil was analyzed using an HP mass spectrometer composed of an AGILENT 7980A chromatograph, an automatic injector and an AGILENT 5975C MSD detector. This device makes it possible to separate and identify molecules with a boiling point below or around $250{ }^{\circ} \mathrm{C}$. This analysis revealed the presence of alkanes and aromatic hydrocarbons, more or less branched, containing 9 to 16 carbon atoms. However, these molecules represents only $8 \%$ by mass of the mixture, the remainder being molecules with a boiling point above $250{ }^{\circ} \mathrm{C}$. A sample of the motor oil was also analyzed using the HP mass spectrometer. A cluster of peaks was visible at the end of the test but it was not possible to identify the molecules present. The motor oil is therefore probably largely made up of molecules with a boiling point above $250{ }^{\circ} \mathrm{C}$.

Samples of the motor and used oil were also analyzed by Fourier transform infrared spectroscopy (FTIR) on a Bruker Vertex 70-Hyperion 2000 spectroscope, which allows to scan the range of wavelengths $4200-400 \mathrm{~cm}^{-1}$. This analysis showed that the majority of hydrocarbons present in the oils are alkanes, although aromatics are also identified.

Analysis of the carbon and hydrogen composition of the oils were carried out by the Leco company on a CHN628 instrument. In addition, the elements contained in the oils were identified by X-ray fluorescence spectrometry, on a Bruker SRS3000 Rx fluorescence instrument at the 4MAT laboratory of the ULB. The measurements were carried out under helium and using a $6 \mu \mathrm{m}$ Mylar film. The evaluation was conducted with SpectraPlus. The masses of each element are expressed as a percentage of the total mass of the sample. The matrix taken into account is composed of alkanes $(\mathrm{CH} 2)$, the mass proportion of which in the mixture is given by the preceding $\mathrm{CHN}$ analysis.

The elemental analysis of the two oils are summarized in Table 1. Besides very comparable hydrocarbon and $\mathrm{S}$ composition, the used oil shows a higher metal content than the motor oil. It seems logical as the used oil was for an unknown amount of time in contact with metal pieces in operation. In addition to the components mentioned in Table 1, the used oil contains several other metals (Mo, Ti, V...), each of them with a mass fraction less $0.02 \mathrm{wt} \%$ and for a total mass fraction of approximately $0.2 \mathrm{wt} \%$. X-ray fluorescence spectrometry does not allow detecting oxygen, but there was surely some in the oils given the presence of metals which were in a certain oxidation state (unknown), and because engine oils may contain alcohols and acids either from their additives [16] or from their use as a lubricant [17]. 
Overall, the results of the analyzes of the composition of the oils do not give a precise picture of them. But they show that the used oil is made up of a wider variety of molecules (organic compounds and metals) than the motor oils, some of them having boiling temperatures below $250{ }^{\circ} \mathrm{C}$.

Table 1. Compositions of the used and motor oil.

\begin{tabular}{ccc}
\hline & Used Oil (wt\%) & Motor Oil (wt\%) \\
\hline $\mathrm{CH}_{2}$ & 90.65 & 90.73 \\
$\mathrm{~S}$ & 4.18 & 4.31 \\
$\mathrm{Ca}$ & 1.32 & 2.43 \\
$\mathrm{Fe}$ & 0.93 & 0.02 \\
$\mathrm{Si}$ & 0.73 & 0.41 \\
$\mathrm{P}$ & 0.76 & 1.13 \\
$\mathrm{Cl}$ & 0.49 & - \\
$\mathrm{K}$ & 0.19 & - \\
$\mathrm{Al}$ & 0.14 & - \\
$\mathrm{Zn}$ & 0.22 & 0.85 \\
$\mathrm{Mg}$ & 0.13 & 0.11 \\
$\mathrm{Cu}$ & 0.05 & 0.01 \\
$\mathrm{Mn}$ & 0.03 & - \\
\hline
\end{tabular}

\subsection{Thermal Analysis Techniques}

\subsubsection{TGA-MS}

The TGA-MS experiments were performed on a Netzsch STA 409PC Luxx coupled with a quadrupole mass spectrometer Netzsch QMS $403 \mathrm{C}$ analyzer. Samples with a mass ranging between 7 and $26 \mathrm{mg}$ were placed in alumina pans and were heated from ambient to $650{ }^{\circ} \mathrm{C}$ at a $10{ }^{\circ} \mathrm{C} \cdot \mathrm{min}^{-1}$ heating rate. The initial air in the device was evacuated before each experiment and a $20 \mathrm{~mL} \cdot \mathrm{min}^{-1}$ helium flux was used to ensure the inert atmosphere in the oven during the experiment. Transfer lines to the MS and the MS instrument itself were set at the instrument standard value of $230{ }^{\circ} \mathrm{C}$. Scans of mass to charge $(\mathrm{m} / \mathrm{z})$ ratios between 10 and 200 were continuously monitored throughout the experiments. The analysis of these signals as a function of the time indicated that mass to charge ratios $36,40,44,55,70,78,84$ and 91 show the highest intensities in comparison with neighboring $\mathrm{m} / \mathrm{z}$ values and always overlap with the decomposition events of the samples detected with the TGA measurements. For this reason, only these signals are shown in this work.

\subsubsection{Pyrolysis Experiments Coupled with GC/MS}

Pyrolysis (Py) experiments were performed using a double shot pyrolizer FrontierLab (PY-2020iD), connected to a gaseous chromatograph (GC), which is subsequently coupled with a quadrupole mass spectrometry (MS) detector and electronic ionization mass detector (GCMS-QP 2010 SE). For all the experiments, the mass of the sample was about $0.5 \mathrm{mg}$. The temperature inside the pyrolizer was kept at $50{ }^{\circ} \mathrm{C}$ for $2.5 \mathrm{~min}$, then raised to $650{ }^{\circ} \mathrm{C}$, with a $20^{\circ} \mathrm{C} \cdot \mathrm{min}^{-1}$ heating rate. The interface temperature was kept $100{ }^{\circ} \mathrm{C}$ above the one of the pyrolizer, up to a maximum of $320^{\circ} \mathrm{C}$. Then, it was kept at this maximum temperature until the end of the analysis. The produced gases were carried by helium at a split ratio of $1 / 100$ and separated using a $30 \mathrm{~m}$ long fused silica capillary column. The GC oven temperature was maintained at $35^{\circ} \mathrm{C}$ for $37.5 \mathrm{~min}$ and then raised with a $5{ }^{\circ} \mathrm{C} \cdot \mathrm{min}^{-1}$ heating rate up to $320^{\circ} \mathrm{C}$ to avoid condensation inside the lines. This temperature was then kept for $10 \mathrm{~min}$. The mass spectra were recorded at $70 \mathrm{eV}$ at a frequency of 2 scans per second. The NIST MS library was used to identify the chemical composition of all evolved species. 


\subsection{Mixture Preparation}

To perform experiments with a mixture of LDPE and oil, a piece of LDPE was first placed on the pan. Then, oil droplets were added. Due to the small size of the samples, mass variations between different samples were unavoidable and a 50:50 mass fraction was difficult to achieve. However, several tests were made with each LDPE/oil combination. Only a few of them are displayed in this paper. Globally, they show that the variation of the proportion of plastic and oil in the mixture between different tests does lead to a significant change of the results. Prior to all the tests, the mass of each component was precisely measured, and it is indicated in all the results.

\section{Results and Discussion}

\subsection{Stabilization Effect of Motor Oils on the Pyrolysis of Plastics}

The results of the thermogravimetric analysis of the pyrolysis of LDPE, motor oil and used oil alone, as well as the results of the analysis of their combined pyrolysis are shown in Figures 1 and 2. These results were presented in a previous paper [11], but they are reproduced here for clarity and further commented. Figure 1 gives the mass of the sample as a function of the temperature, while Figure 2 gives the mass loss per unit of time of the sample, as a function of the temperature. Figures 1 and 2 also report "theoretical" decomposition curves of the mixtures. These theoretical decomposition curves are calculated as the sum of the TGA curves of the components alone, multiplied by their initial weight fraction in the mixture.
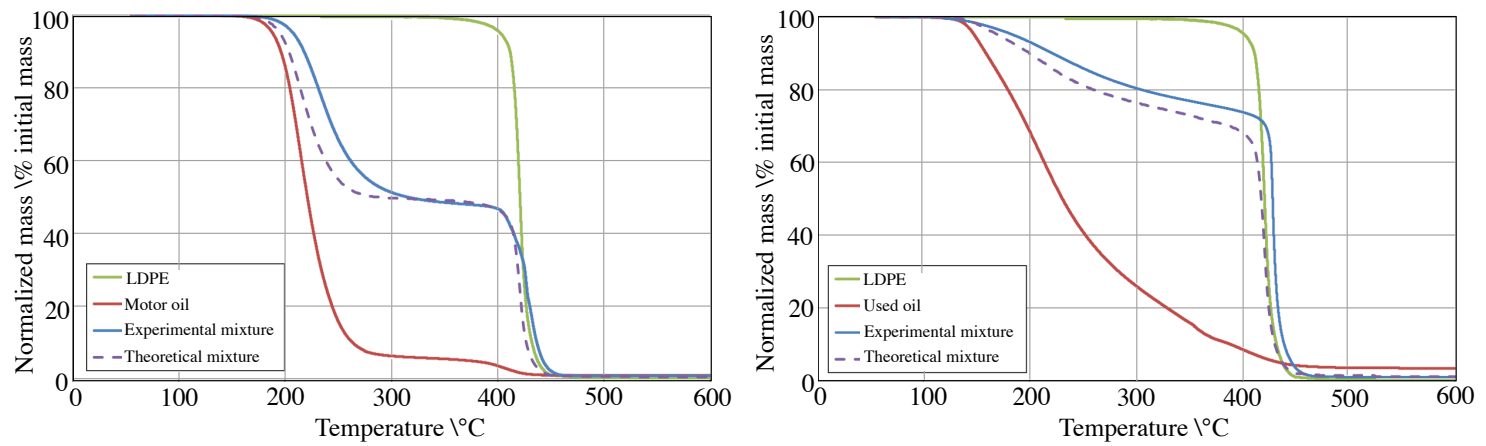

Figure 1. Thermogravimetric analysis of LDPE, motor oil, used oil and the two mixtures of oil and plastic, with a heating rate of $10{ }^{\circ} \mathrm{C} \cdot \mathrm{min}^{-1}$. Mass of the sample as a function of the temperature. Left column: mixture of LDPE and motor oil (45 wt\% of LDPE). Right column: mixture of LDPE and used oil (67 wt $\%$ of LDPE).
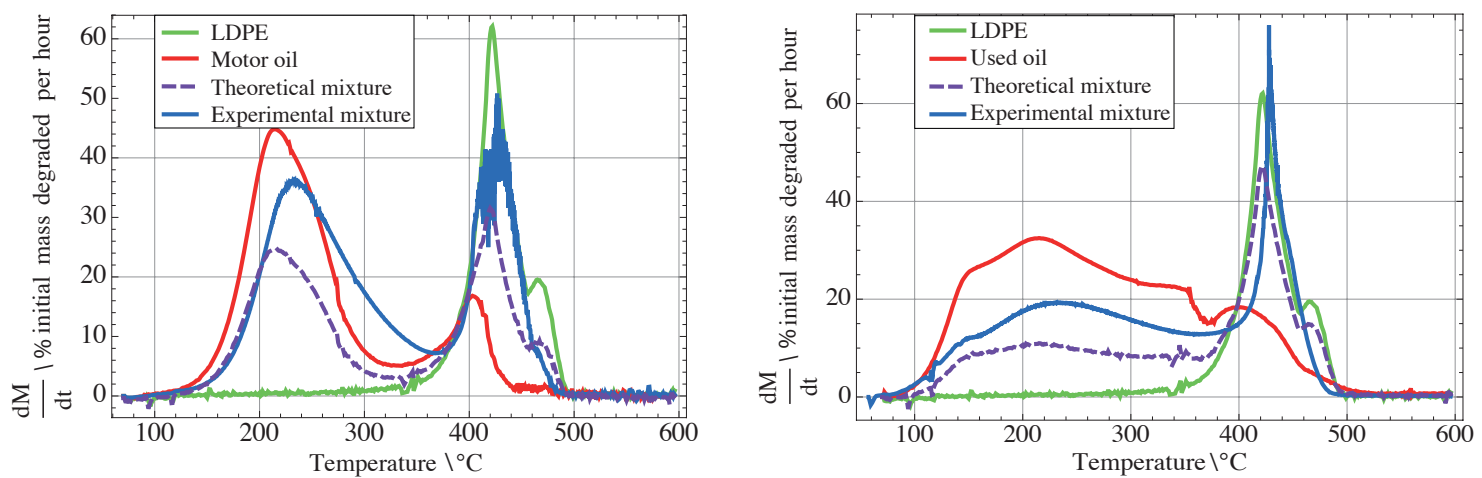

Figure 2. Thermogravimetric analysis of LDPE, motor oil, used oil and the two mixtures of oil and plastic, with a heating rate of $10^{\circ} \mathrm{C} \cdot \mathrm{min}^{-1}$. Time derivative of the mass of the sample (expressed as the $\%$ of the initial mass degraded per hour), as a function of the temperature. Left column: mixture of LDPE and motor oil (45 wt \% of LDPE). Right column: mixture of LDPE and used oil ( $67 \mathrm{wt} \%$ of LDPE). 
Logically, we see in Figure 1 that the degradation of the used oil takes place over a wider range of temperature than the degradation of the motor oil. It starts at a lower temperature and ends at a higher one. This is also highlighted in Figure 2: during the degradation of the motor oil, the mass loss per unit of time reaches $45 \%$ of the initial mass degraded per hour, while it is only around $30 \%$ for the used oil. This is a consequence of the difference in purity of both oils. The weight of the used oil decays slowly, originating both from volatilization of constituents and decomposition of polymer-like chains.

The results presented in Figure 1 show also that the degradation of the mixtures clearly occurs in two distinct steps: the first step corresponding to the degradation of the oil and a second one corresponding to the degradation of the plastic. Coherently, we see in Figure 2 that the mass loss per unit time of the mixtures presents two maxima as a function of the temperature.

Moreover, these results show an interaction between the components during their pyrolysis, leading to a stabilization of the mixtures. Indeed, Figure 1 shows that the experimental TGA curves of the samples (continuous blue lines) are shifted to the right when compared to the theoretical curves (dashed lines). During the decomposition step of the oil, the temperature required to reach $90 \%$ of the initial mass of the sample is shifted to higher values by about $20{ }^{\circ} \mathrm{C}$ for both mixtures. During the decomposition step of the LDPE, this shift is less intense. But it can be observed for instance that the temperature at which $30 \%$ of the initial mass is reached is shifted to higher values by about $5{ }^{\circ} \mathrm{C}$ for the mixture with the motor oil and by about $10{ }^{\circ} \mathrm{C}$ for the mixture with the used oil. Coherently, Figure 2 shows that the two maxima of the mass loss per unit of time are shifted to the right, when the experimental TGA curves of the mixtures are compared to the theoretical ones. This is very clear regarding the decomposition step of the oil (shift of approximately $35^{\circ} \mathrm{C}$ ) but less regarding the decomposition step of the LDPE (shift of about $10^{\circ} \mathrm{C}$ ). These increased decomposition peak temperatures most likely indicate a change in the chemical composition of the pyrolysis products, due to an interaction between oil and plastic. As the decomposition of the LDPE is only slightly affected by this interaction, it means that the chemical bonds created during the interaction between the oils and the plastic are not stabilizing the polymeric material; this could have been expected with charring polymers. Such an interaction between LPDE and oil has also been reported by Aboulkas et al. for mixtures of oil shale and plastics [18]. However, these authors did not provide a chemical description of the interactions between the polymer and the oils, leading to the shift towards higher temperature of the decomposition peaks. Repeated tests on different TGA instruments, including a High-Resolution TGA apparatus, showed identical trends [11], which we examine in the next sections with various measuring apparatus (TGA-MS and Py-GCMS).

\subsection{Species Characterization by TGA-MS}

Figure 3 shows the TGA-MS experiments on LDPE, motor oil, used oil and the two mixtures of plastic and oil (32 wt \% of LDPE and $68 \mathrm{wt} \%$ of motor oil; $36 \mathrm{wt} \%$ of LDPE and $64 \mathrm{wt} \%$ of used oil). Samples masses and the current intensities of the main $\mathrm{m} / \mathrm{z}$ traces detected are shown as functions of the temperature.

For LDPE, the temperature corresponding to the peak of detection of gaseous products in the mass spectrometry (around $450{ }^{\circ} \mathrm{C}$ ) is close to the one observed on the TGA analysis of LPDE (see Figures 1 and 2). During the decomposition of pure LDPE, the $\mathrm{m} / \mathrm{z}$ ratios that resulted in the highest intensities in detection rate are 40,55 and 70. These are indicators of aliphatic hydrocarbons possessing 3, 4 and 5 carbon atoms.

During the pyrolysis of the motor oil, the evolved species are mostly detected at higher temperatures (around $400{ }^{\circ} \mathrm{C}$, see Figure 3) than the temperatures at which the mass loss is observed (mostly between $250{ }^{\circ} \mathrm{C}$ and $350{ }^{\circ} \mathrm{C}$, see Figure 3). This might be an artefact explained by the presence of heavy residues in the pipes leading to the MS detector, delaying the gas analysis. Regarding the ratios mass to charge detected, the pyrolysis of the oils leads mainly to the formation of aliphatic chains, resulting in the $\mathrm{m} / \mathrm{z}$ traces 40,55 and 70 . This appearance of identical traces for both plastic and oil decompositions will make it difficult to distinguish newly produced compounds during their 
co-pyrolysis, unless profound changes in $m / z$ traces happen. Finally, we can also observe that the pyrolysis of the used oil leads to the detection of two distinct peaks for the $m / z=40$ trace.
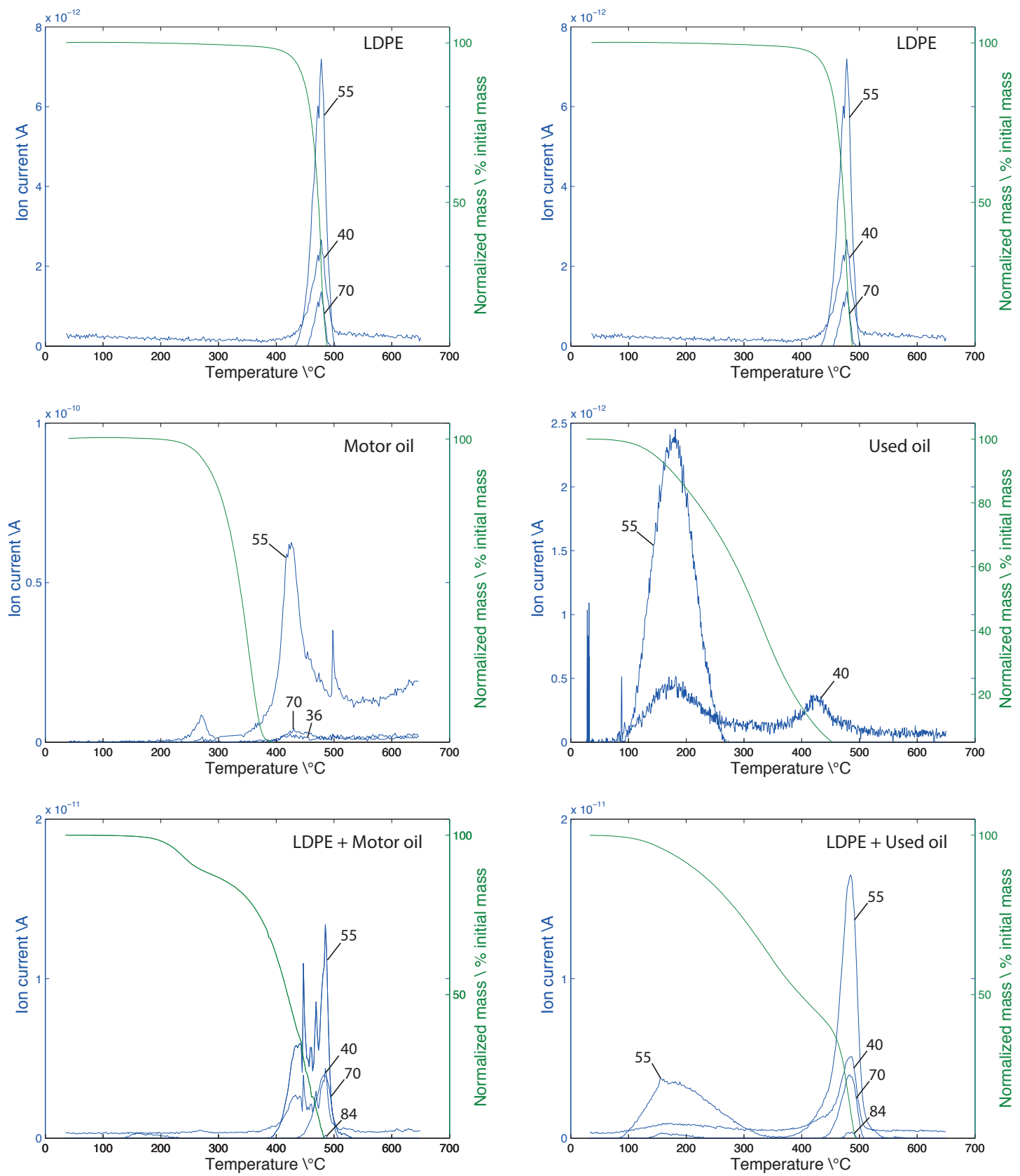

Figure 3. TGA-MS experiments performed on LDPE, motor oil, used oil and mixtures of plastic and oil. The $m / z$ traces shown are $36,40,55,70$, and 84 .

The pyrolysis of the mixtures of LDPE and oil reveals identical $\mathrm{m} / \mathrm{z}$ traces than during the pyrolysis of the components alone, except for the appearance of $\mathrm{m} / \mathrm{z}=84$. This trace is absent during the pyrolysis of the pure LDPE and the pure oils. Therefore, the molecule associated with this fragment could be related to interactions between the oil and the plastic during their co-pyrolysis. As shown in Figure 4 (which is a zoom on Figure 3), this fragment is detected at a temperature close to $480{ }^{\circ} \mathrm{C}$ (i.e., during the decomposition of the LDPE). However, because the intensity of the signal is far too low to detect any other fragments belonging to this molecule, it is impossible to determine its chemical structure. 


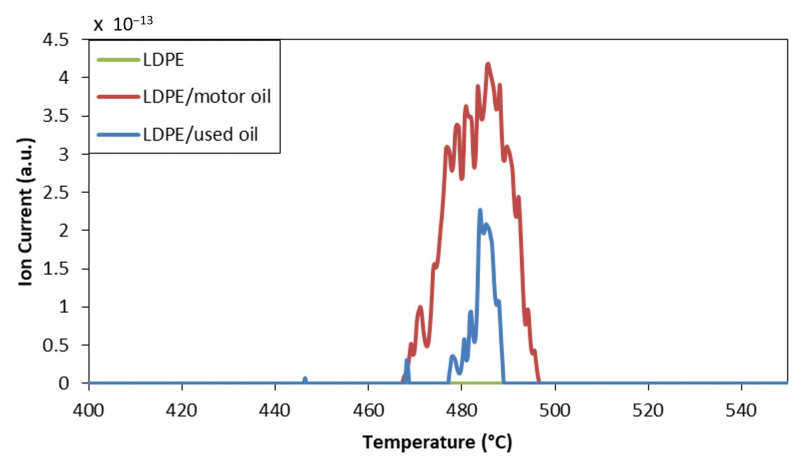

Figure 4. Evolution of $\mathrm{m} / \mathrm{z} 84$ during the decomposition of pure LDPE and LDPE-oil mixtures, as measured with TGA-MS.

The sensitivity of TGA-MS seems to be insufficient to detect the existence of chemical species that could explain the interaction between oil and plastic during their thermal decomposition, increasing their thermal stability. Furthermore, the complexity of the oils makes a clear identification of the gaseous compounds eluting from the sample nearly impossible. This is in line with the study of Singh et al. who compared different published pyrolysis tests and the combined analysis of TGA-MS (and also TGA-FTIR) data and their shortcomings [19]. For this reason, a different approach, presented in the next section, was tested. It is composed of two steps. The first one is a complete pyrolysis of the material. Then, the produced molecules are eluted later in a GC-MS instrument. As such, the material is not continuously decomposed as is the case of a TGA-MS instrument, potentially increasing compositional sensitivity [20]. This methodology is also referred to as pyrolysis-GC/MS or Py-GC/MS. The heating rate is not altered drastically in this test (a heating rate of $20^{\circ} \mathrm{C} \cdot \mathrm{min}^{-1}$ compared to $10^{\circ} \mathrm{C} \cdot \mathrm{min}^{-1}$ for the TGA-MS experiments), and therefore the decomposition mechanism is expected to be identical.

\subsection{Species Identifications and Discussion Based on Py-GC/MS Analysis}

As mentioned previously, in the Py-GC/MS technique, all the volatiles produced during the pyrolysis are first collected and then injected into a GC column followed by a MS analyzer. Consequently, information regarding the thermal stability is lost. However, all the chemical compounds produced during the pyrolysis are analyzed in much greater detail and with a higher sensitivity. This should increase the probability of chemically identifying the volatiles produced during the pyrolysis of the LDPE/oil mixtures.

In Figures 5 and 6, the chromatograms for the LPDE, the two types of oil, a mixture of LDPE and motor oil (70 $\mathrm{wt} \%$ of LDPE) and a mixture of LDPE and used oil (50 wt $\%$ of LDPE) are shown. Such a chromatogram presents, as a function of the retention time, the highest $m / z$ value observed on the corresponding mass spectrum. Indeed, when trying to identify the molecules on a spectrum obtained from Py-GC/MS, it should be kept in mind that, prior to reaching the spectrometer, the molecules are injected and retained in a GC-column. Therefore, it is considered that the molecular weight of a molecule exiting the column at a given time is equal to the highest $\mathrm{m} / \mathrm{z}$ value observed on the corresponding mass spectrum. Consequently, each peak in a chromatogram marks the presence of a molecule with a certain molecular weight.

The instrument used here, with its current settings, separates similar hydrocarbons with a difference of one carbon in their structure by roughly two minutes. Therefore, even if their spectra are quite similar, a distinction can be made between two molecules if the respective spectra are combined with information regarding their retention time. For instance, considering an alkane of a given molecular weight, a molecule eluting two minutes later presenting a similar spectrum is also an alkane, possessing one more carbon atom in its structure. For every observed small deviation in elution time intervals, changes in chemistry are expected, such as type or amount of atoms. Because elutriation 
takes place prior to molecules reaching the detector, the mass spectrum obtained at a given time can be studied and compared to existing databases to allow identifying the corresponding molecule.

The shape of the chromatogram obtained for LDPE is coherent with the fact that, during its thermal degradation, LDPE decomposes following a random scission mechanism that leads to a fragmentation of the initial polymer chain into smaller straight alkanes, alkenes and dienes, containing between 9 and 36 carbon atoms [21]. Consequently, the chromatogram should be composed of several triplets of peaks, with two minutes between two successive triplets. This is indeed observed in Figure 5 (top figure) and in Figure 7 (top figure), which is a focus on the Py-GC/MS chromatogram of LDPE, between retention times 70.5 and $74 \mathrm{~min}$. On the latter, two alkanes, $\mathrm{C}_{20} \mathrm{H}_{42}$ (molecular weight $\left.282 \mathrm{~g} \cdot \mathrm{mol}^{-1}\right)$ and $\mathrm{C}_{21} \mathrm{H}_{44}\left(296 \mathrm{~g} / \mathrm{mol}^{-1}\right)$, and the corresponding alkenes and dienes, can be observed.

The chromatograms of the two oils show much less structure than the one of LDPE, with a lot of material coming out at each elution time, starting from $50 \mathrm{~min}$ for the used oil and $75 \mathrm{~min}$ for the motor oil (see Figures 5 and 6, middle figures). Alkane species are also eluted, as shown by the peak of the mass fraction 282 and 296 in Figure 7 (middle figures), which are focus on the Py-GC/MS chromatograms of the motor oil and the used oil, between retention times 70.5 and $74 \mathrm{~min}$. Other species also elute from the oils, as it can be observed by the much less stable baseline, as compared to the LDPE, in Figures 5 and 6 (middle figures). However, the peak intensities of the individual MS spectra are too low for a proper identification of these species.
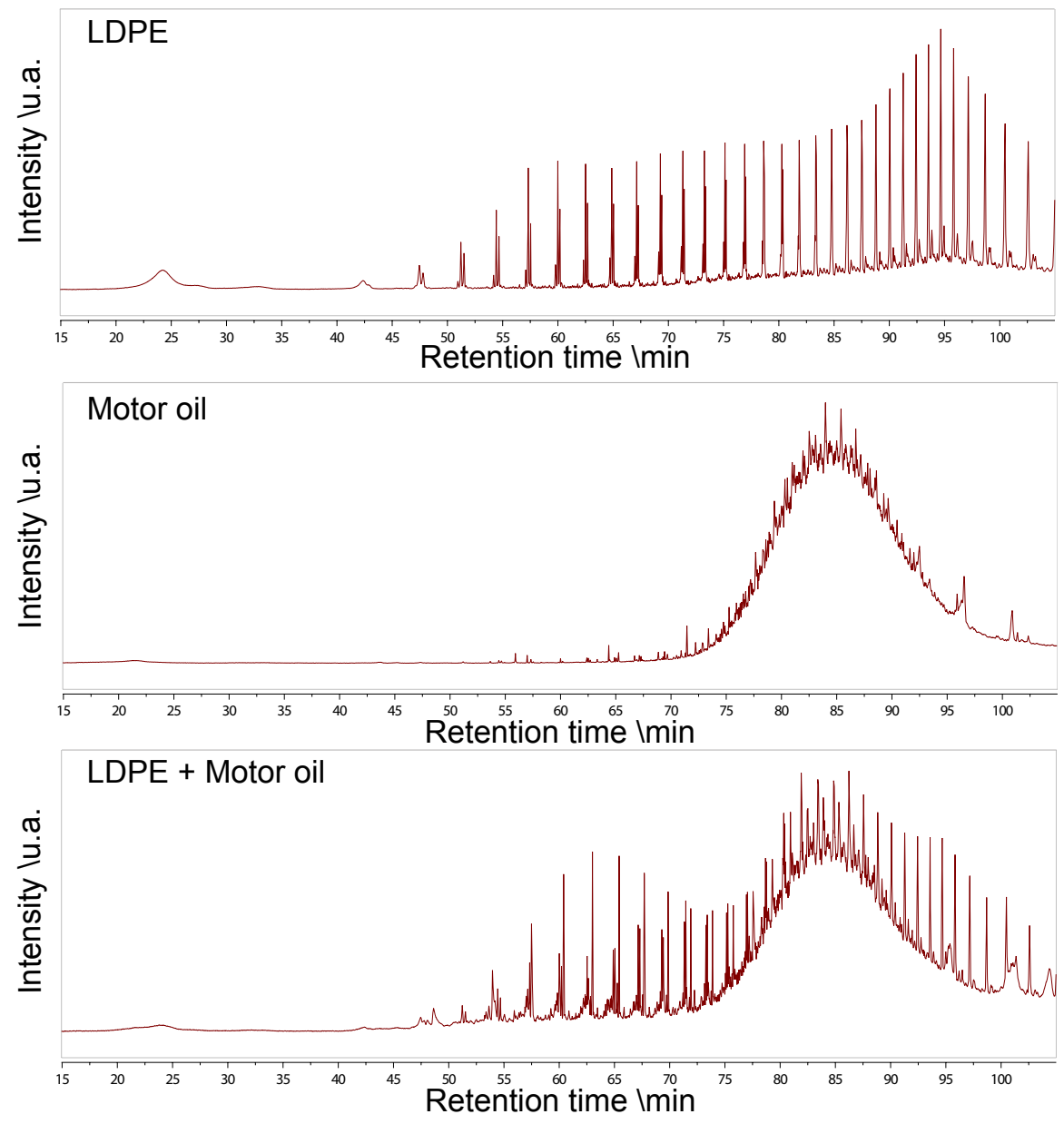

Figure 5. Resulting chromatograms of the Pyrolysis coupled to gaseous chromatograph and mass spectrometry (Py-GC/MS) experiments performed on LDPE, motor oil, and a mixture of motor oil and LDPE (70 $w \mathrm{t} \%$ of LDPE). 

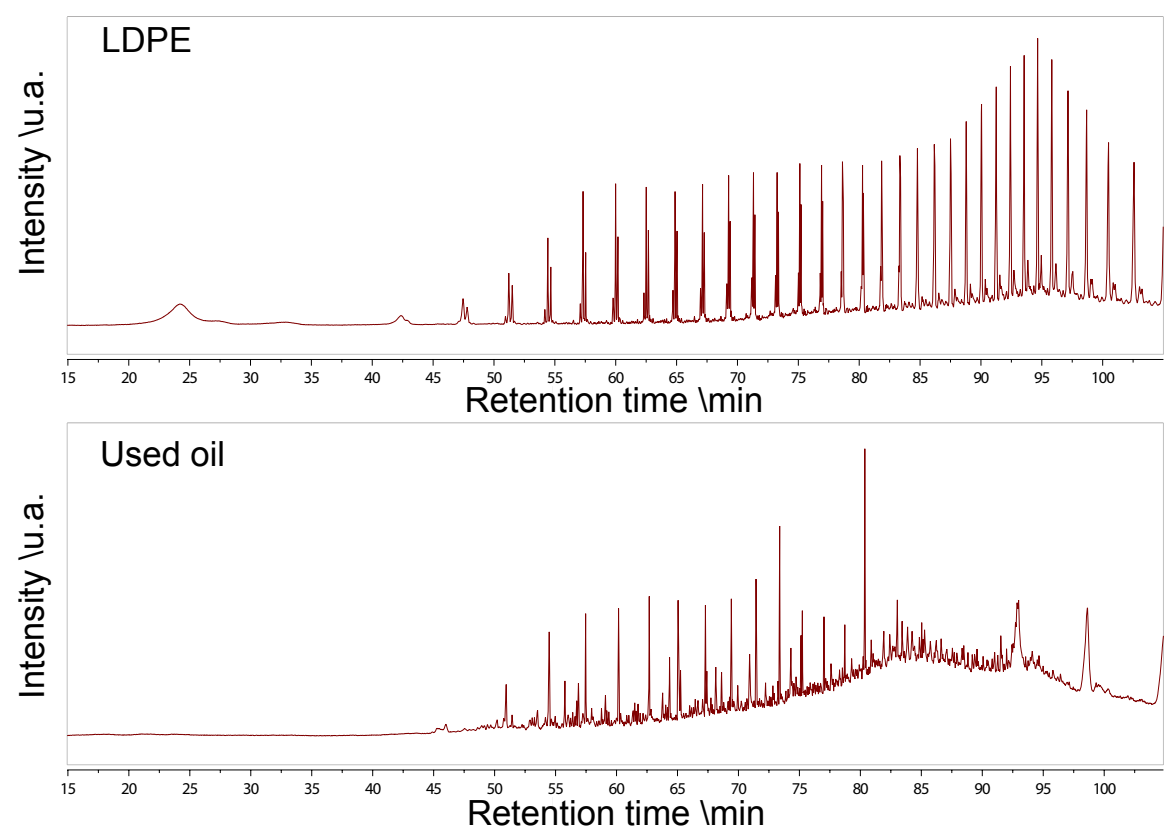

LDPE + Used oil

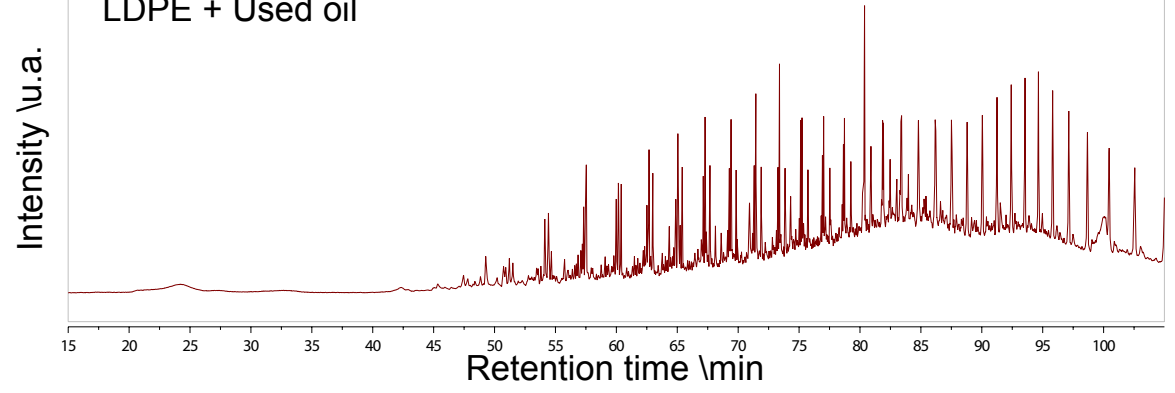

Figure 6. Resulting chromatograms of the Py-GC/MS experiments performed on LDPE, used oil, and a mixture of used oil and LDPE (50 $\mathrm{wt} \%$ of LDPE).

In Figure 7 (bottom), focus on the Py-GC/MS chromatograms of the co-pyrolysis of LDPE/motor oil and LDPE/used oil, between retention times 70.5 and $74 \mathrm{~min}$, are presented. On these chromatograms, peaks corresponding to the triplets diene, alkene and alkane, typical of LDPE pyrolysis products, are easily identified. Next to these triplets, an intense peak is also systematically observed, corresponding to molecules eluting $0.4 \mathrm{~min}$ after each triplet. The chemical analysis of these peaks using the corresponding individual MS spectra shows a best match with aldehyde species. For instance, in Figure 8, the MS spectrum of dodecanal (aldehyde $C_{12}$ ), from the NIST library, is compared to the one of the molecule eluting at $63 \mathrm{~min}$.

The sequence diene-alkene-alkane-aldehyde has been observed for the range of hydrocarbons $\mathrm{C}_{12}$ (dodecanal) to $\mathrm{C}_{28}$ (octacosanal), at elution times prior to $75 \mathrm{~min}$. At higher $\mathrm{m} / \mathrm{z}$ ratios, the oil fragments start to elute most intensely, and co-elution makes the analysis difficult. Because no peak corresponding to aldehydes was observed when the pyrolysis products of the pure plastic and the pure oils were analyzed, the aldehydes appear to result from chemical interactions between the decomposition products of the plastic and the oils. Due to the high variety of hydrocarbons present in the oils, a full investigation of the exact molecular structure of these aldehydes was however not performed, as the formation of aldehyde groups during decomposition occurred on hydrocarbons of different chain lengths. In total 13 aldehyde species could be found with $\mathrm{m} / z$ ion fragments between 200 and 400 for the LDPE/used oil mixture. 

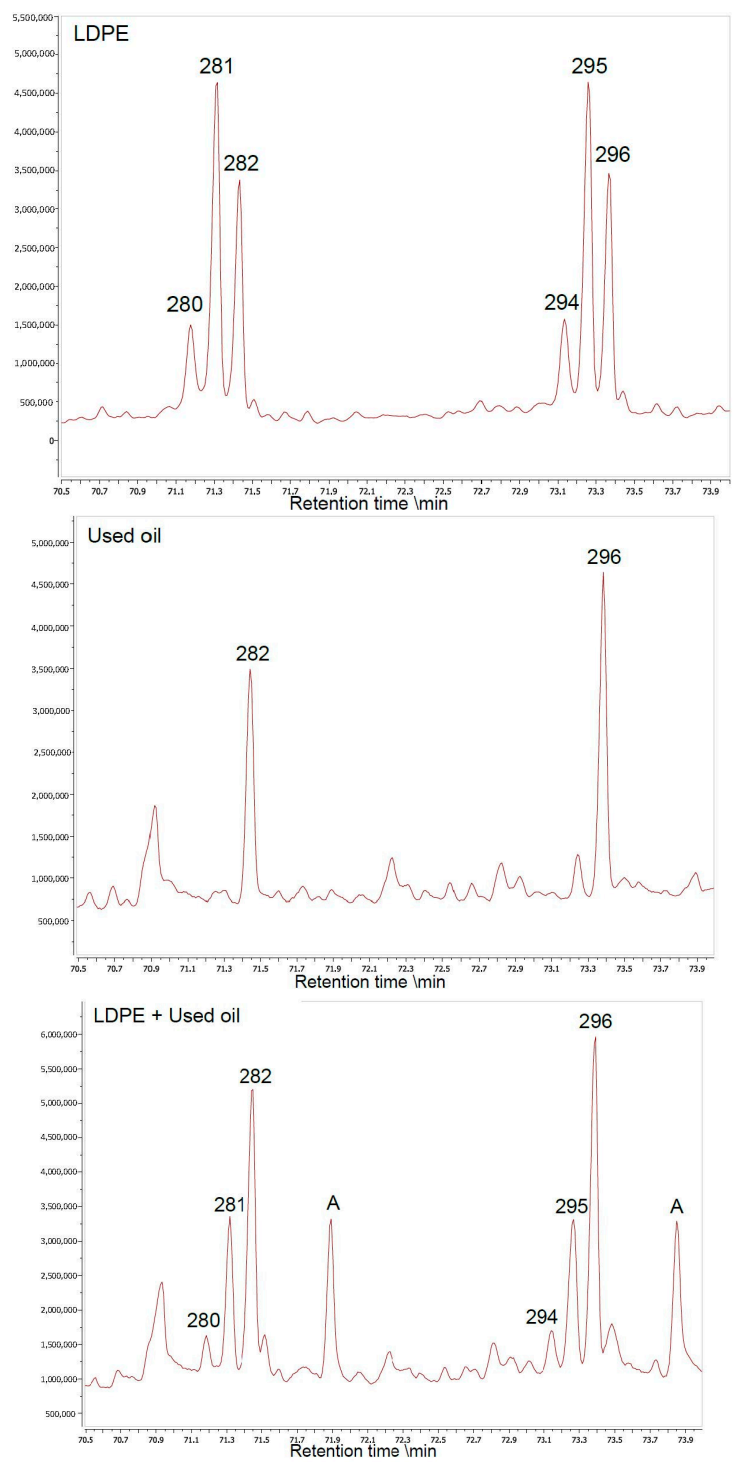
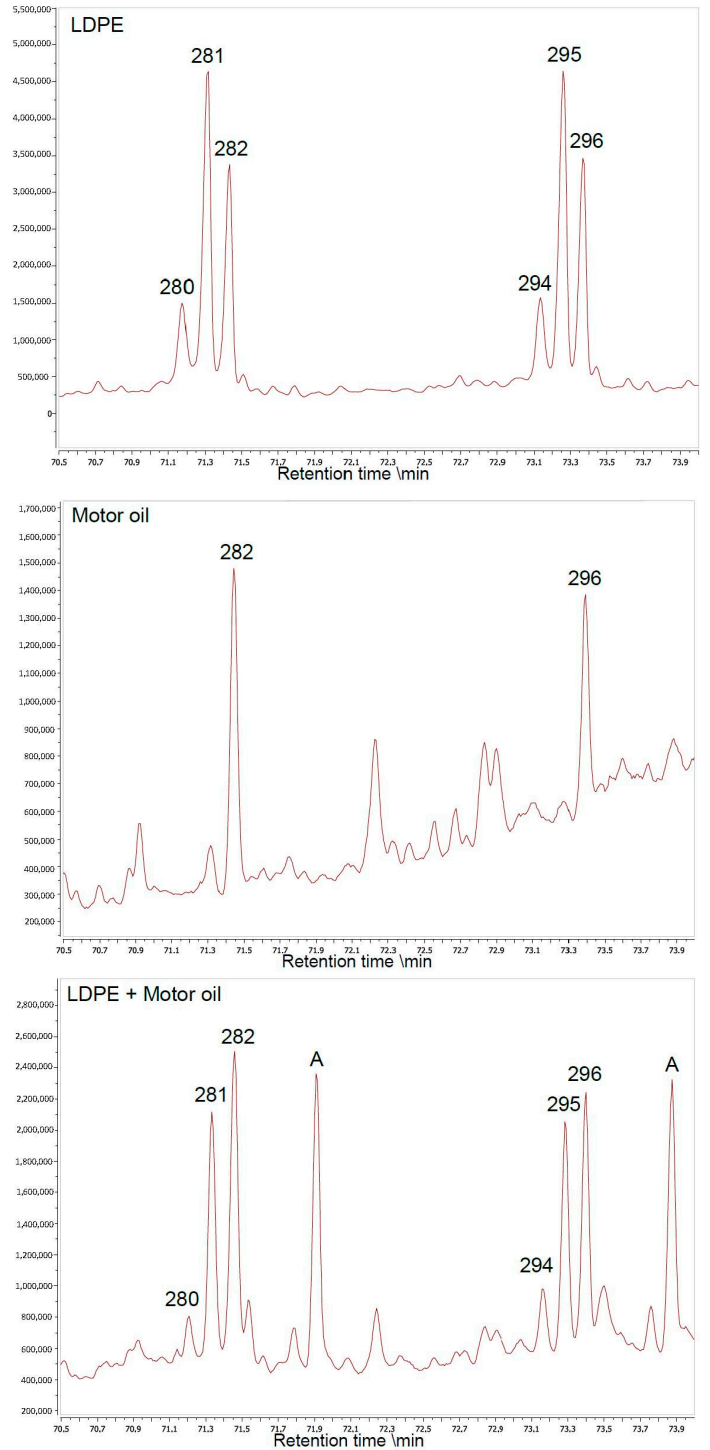

Figure 7. Focus on the Py-GC/MS chromatograms of Figures 5 and 6, between retention times 70.5 and $74 \mathrm{~min}$. The $\mathrm{m} / \mathrm{z}$ ratio is indicated at the top of each peak when known. A indicates the aldehydes.

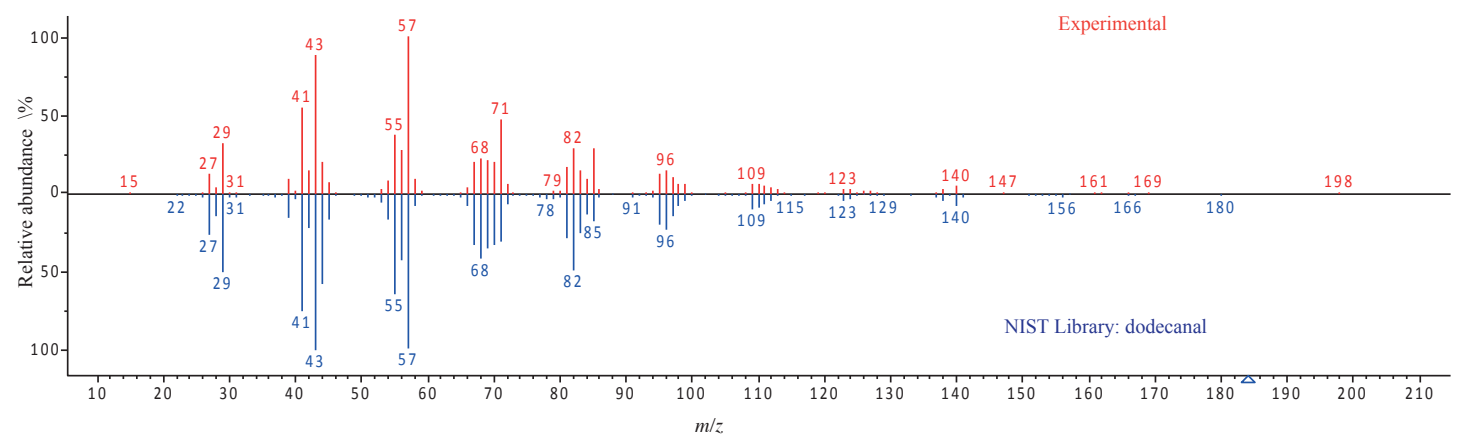

Figure 8. Comparison between the experimental MS spectrum of molecule A, eluting at 63 min during the Py-GC/MS analysis of a mixture of LDPE and used oil, and the spectrum of dodecanal as found in the NIST library. 


\subsection{Co-Pyrolysis Interaction Mechanism}

The formation of aldehydes as byproducts of pyrolysis can only be mediated by the presence of molecules containing oxygen, in both oils, as remaining oxygen was always completely evacuated from the atmosphere prior to each test. As mentioned previously, both oils certainly contain oxygen, given the presence of metals which are in a certain oxidation state, and because it is known that lubrication oils may contain both acids and alcohols. As we do not have a fine picture of the chemical composition of these oils, it is difficult to propose a precise mechanism for the formation of these aldehydes. Nevertheless, by way of example, if alcohol groups are present within certain molecules in the oils, a mechanism can be proposed, shown in Figure 9, where these groups interact with radicals formed during the LDPE decomposition, creating aldehyde groups on chains of various lengths, which are then cracked and thus found in the Py-GC/MS chromatograms. Regarding the oxidized metals, it is worth to point out that Shah et al. [22] reported the formation of aldehydes during the catalytic pyrolysis of LDPE, using oxide containing catalysts such as magnesium oxide or zinc oxide, both of them being present in our used and motor oils (see Table 1). Also and more generally, as mentioned previously, a stabilization effect during the co-pyrolysis of LPDE and oil has been reported by Aboulkas et al. [18]. However, these authors do not provide a chemical description of the interactions between the polymer and the oil; they only describe the shift towards higher temperature of the decomposition peaks during the pyrolysis.

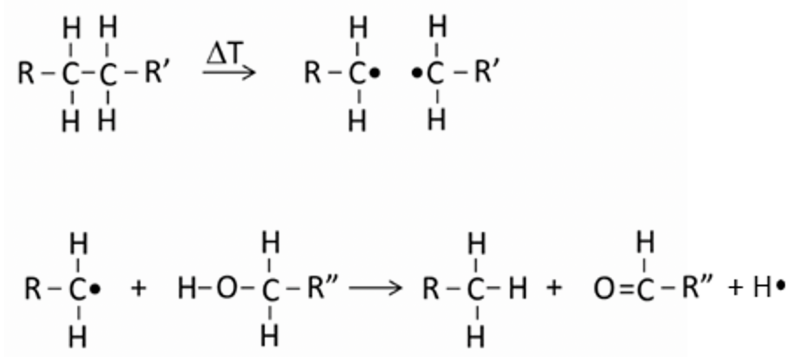

Figure 9. Proposed reaction mechanism between radicals produced during decomposition and alcohols in the oils, leading to the formation of aldehydes.

The overall change in chemical composition during pyrolysis reveals the increased thermal stability of the mixtures: plastic and oil interact chemically, creating a more thermally stable condensed phase, which then degrades, partially, as aldehydes. However, their presence in the pyrolysis products is not high enough, compared to the intense degradation peak of LDPE, to be detected using in-line gas analysis during degradation tests. The TGA-MS did pick up a new signal, as shown in Figure 4, but due to the low peak intensity and molecule fragmentation, the actual chemical structure of the found molecule could not be revealed. Only the full collection of the decomposition material and the intense analysis of the GC/MS made it possible to detect the presence of these aldehydes.

\section{Conclusions}

Different thermal analyses have been performed on LDPE, two types of motor oil (new and used) and mixtures of LDPE and each of these oils, in order to study the interactions that take place between LDPE and oil during their co-pyrolysis. It is shown that plastic and oil stabilize each other, as the degradation of both materials is postponed during their co-pyrolysis. However, TGA coupled with MS lacks sufficient sensitivity to detect any chemical differences in the composition of the degraded materials. Pyrolysis tests gathering all the gaseous products followed by injection into a GC-MS analyzer, however, revealed the production of aldehydes species upon the co-pyrolysis of plastic and the oils. It is for example suggested that these aldehydes are produced by the reaction of the alcohols present in the lubricants with the LDPE products of degradation or by the interaction between the LDPE and oxidized metals in the oils. 
Author Contributions: Conceptualization, S.B. and B.R.; methodology, S.B. and B.R.; validation, S.B., B.R. and O.V.; formal analysis, S.B., B.H., B.R. and O.V.; investigation, S.B., B.H., B.R. and O.V.; writing-original draft preparation, S.B. and B.R.; writing-review and editing, S.B., B.H., B.R. and O.V.; supervision, B.H. and B.R.; funding acquisition, B.H. All authors have read and agreed to the published version of the manuscript.

Funding: This research received no external funding.

Acknowledgments: The authors are graceful to the FYSC lab (Physical Chemistry and Polymer Science) at the VUB, the 4MAT at the ULB and the Group R2Fire (Unité Matériaux et Transformations) at the ENSCL for providing the thermal analyzers and for fruitful discussions.

Conflicts of Interest: The authors declare no conflict of interest.

\section{Abbreviations}

The following abbreviations are used in this manuscript:

GC Gaseous Chromatograph

LDPE Low-Density Polyethylene

MS Mass Spectrometry

Py Pyrolysis

TGA Thermogravimetry

\section{References}

1. Achilias, D.; Roupakias, C.; Megalokonomos, P.; Lappas, A.; Antonakou, E. Chemical recycling of plastic wastes made from polyethylene (LDPE and HDPE) and polypropylene (PP). J. Hazard. Mater. 2007, 149, 536-542. [CrossRef] [PubMed]

2. Zhou, L.; Wang, Y.; Huang, Q.; Cai, J. Thermogravimetric characteristics and kinetic of coal/plastic blends co-pyrolysis. Fuel Process. Technol. 2006, 87, 963-969. [CrossRef]

3. Paradela, F.; Pinto, F.; Gulyurtlu, I.; Cabrita, I.; Lapa, N. Study of the co-pyrolysis of biomass and plastic wastes. Clean Technol. Environ. Policy 2009, 11, 115-122. [CrossRef]

4. Abnisa, F.; Daud, W. A review on co-pyrolysis of biomass: An optional technique to obtain a high-grade pyrolysis oil. Energy Convers. Manag. 2014, 87, 71-85. [CrossRef]

5. Oyedun, A.; Tee, C.; Hanson, S.; Hui, C. Thermogravimetric analysis of the pyrolysis characteristics and kinetics of plastics and biomass blends. Fuel Process. Technol. 2014, 128, 471-481. [CrossRef]

6. Aboulkas, A.; Makayssi, T.; Bilali, L.; El Harfi, K.; Nadifiyine, M.; Benchanaa, M. Co-pyrolysis of oil shale and plastics: Influence of pyrolysis parameters on the product yields. Fuel Process. Technol. 2012, 96, $209-213$. [CrossRef]

7. Suriapparao, D.; Ojha, D.; Ray, T.; Vinu, R. Kinetic analysis of co-pyrolysis of cellulose and polypropylene. J. Therm. Anal. Calorim. 2014, 117, 1441-1451. [CrossRef]

8. Chen, W.; Shi, S.; Zhang, J.; Chen, M.; Zhou, X. Co-pyrolysis of waste newspaper with high-density polyethylene: Synergistic effect and oil characterization. Energy Convers. Manag. 2016, 112, 41-48. [CrossRef]

9. Uçar, S.; Ozkan, A.; Karagoz, S. Co-pyrolysis of waste polyolefins with waste motor oil. J. Anal. Appl. Pyrolysis 2016, 233-241. [CrossRef]

10. Kim, S.; Kim, J.; Jeon, J.; Park, Y.; Park, C. Non-isothermal pyrolysis of the mixtures of waste automobile lubricating oil and polystyrene in a stirred batch reactor. Renew. Energy 2013, 54, 241-247. [CrossRef]

11. Breyer, S.; Mekhitarian, L.; Rimez, B.; Haut, B. Production of an alternative fuel by the co-pyrolysis of landfill recovered plastic wastes and used lubrication oils. Waste Manag. 2017, 60, 363-374. [CrossRef] [PubMed]

12. Castaldo, R.; De Falco, F.; Avolio, R.; Bossanne, E.; Cicaroni Fernandes, F.; Cocca, M.; Di Pace, E.; Errico, M.; Gentile, G.; Jasinski, D.; et al. Critical Factors for the Recycling of Different End-of-Life Materials: Wood Wastes, Automotive Shredded Residues, and Dismantled Wind Turbine Blades. Polymers 2019, 11, 1604. [CrossRef] [PubMed]

13. Avella, M.; Avolio, R.; Bonadies, I.; Carfagna, C.; Errico, M.; Gentile, G. Effect of compatibilization on thermal degradation kinetics of HDPE-based composites containing cellulose reinforcements. J. Therm. Anal. Calorim. 2010, 102, 975-982. [CrossRef] 
14. Rimez, B.; Rahier, H.; Biesemans, M.; Bourbigot, S.; Van Mele, B. Flame retardancy and degradation mechanism of poly(vinyl acetate) in combination with intumescent flame retardants: I. Ammonium poly(phosphate). Polym. Degrad. Stab. 2015, 121, 321-330. [CrossRef]

15. Rimez, B.; Rahier, H.; Biesemans, M.; Bourbigot, S.; Van Mele, B. Modelled decomposition mechanism of flame retarded poly(vinyl acetate) by melamine isocyanurate. J. Therm. Anal. Calorim. 2017, 127, 2315-2324. [CrossRef]

16. Madanhire, I.; Mbohwa, C. Mitigating Environmental Impact of Petroleum Lubricants; Springer International Publishing: Cham, Switzerland, 2016.

17. Liu, Z.; Wang, H.; Zhang, L.; Sun, D.; Cheng, L.; Pang, C. Composition and degradation of turbine oil sludge. J. Therm. Anal. Calorim. 2016, 125, 155-162. [CrossRef]

18. Aboulkas, A.; El Harfi, K.; Nadifiyine, M.; El Bouadili, A. Investigation on pyrolysis of Moroccan oil shale/plastic mixtures by thermogravimetric analysis. Fuel Process. Technol. 2008, 89, 1000-1006. [CrossRef]

19. Singh, S.; Wu, C.; Williams, P.T.; Pyrolysis of waste materials using TGA-MS and TGA-FTIR as complementary characterisation techniques J. Anal. Appl. Pyrolysis 2012, 94, 99-107. [CrossRef]

20. Tsugoshi, T.; Nagaoka, T.; Hino, K.; Arii, T.; Inoue, M.; Shiokawa, Y.; Watari, K. Evolved gas analysis-mass spectrometry using skimmer interface and ion attachment mass spectrometry. J. Therm. Anal. Calorim. 2005, 80, 787-789. [CrossRef]

21. Serrano, D.; Aguado, J.; Escola, J.; Rodriguez, J.; San Miguel, G. An investigation into the catalytic cracking of LDPE using Py-GC/MS. J. Anal. Appl. Pyrolysis 2005, 74, 370-378. [CrossRef]

22. Shah, J.; Jan, R.; Mabood, F.; Jabeen, F. Catalytic pyrolysis of LDPE leads to valuable resource recovery and reduction of waste problems. Energy Convers. Manag. 2010, 51, 2791-2801. [CrossRef]

Publisher's Note: MDPI stays neutral with regard to jurisdictional claims in published maps and institutional affiliations. 